551. $21: 550.341 .2$

\title{
A Study of Earthquakes in Relation to Volcanic Activity (I)
}

-Earthquakes That Occurred during the Formation Period of a New Dome "Showa-Shinzan" and Their Forerunners near Volcano Usu-

by

T. Kizawa

Meteorological Research Institute

(Received July 9, 1957)

\begin{abstract}
Showa-Shinzan, one of the Belonite-Volcanoes, born (1943-1945) in the eastern part of the Volcano Usu (in the South-western part of Hokkaido, Japan) is famous in the history of volcanoes in the world.

This volcano erupted in a farm-land and further developed a lava dome (Spine) in the central part. It is a Pelée-type one, and its developing process was clearly observed for the whole period.

Some remarkable earthquake swarms occurred during the volcanic activity, and the major ones among them were recorded by seismographs even at a station about $800 \mathrm{~km}$ apart from the volcano.

The author investigated the relations between the occurrence of earthquakes and the formation of Showa-Shinzan and tried to find some clues to the volcanic mechanism. In this first paper, after an investigation of the characteristics of earthquake swarms recorded on the seismographs in Muroran, Mori and Sapporo (epicentral distance: 25-69 $\mathrm{km}$ ) and the relation of the volcanic activity therewith, some interesting results were obtained:

1) Daily earthquake frequency diagram for the whole period of twenty three months were prepared for the first time.

2) These earthquakes were clearly divided into the following three stages:

(i) Pre-volcanic stage: In this stage there was no eruption, and remarkable earthquakes occurred around Volcano Usu frequently. The relation between the maximum amplitude $(A)$ in these earthquake swarms and their frequency $(N)$ was expressed by

$$
N A^{m}=\text { const. }
$$

where $m$ is about 1.8 , similar to that of the tectonic earthquake. Moreover, the migration of the hypocentres of these earthquakes showed an intimate connection with the course of the magma intrusion.

(ii) Stage of eruptive activity: A violent eruption occurred in the central part of the rising area. The extremely shallow earthquakes during the period of six months including just before and through the eruptive activity were proved to have been originated at the area adjacent to the newly formed crater.

(iii) Birth and development of lava dome (spine): The lava dome grew and developed without eruption, accompanied with numer" ous earthquakes. The earthquakes, which differed greatly from those
\end{abstract}


at the former two stages, began to occur almost simultaneously with the end of the eruption and the frequencies of the earthquakes during the following twelve months corresponded closely to the speed of the development of the lava dome. The value of $m$ in this case was 3.5.

3) Process of magma intrusion, increase of magma viscosity and their relationship with the feature change of earthquake swarms were investigated. The possibility of predicting volcanic activity Volcano Usu by seismograph at stations up to approximately sixty or seventy kilometers from the volcano is suggested.

\section{Introduction}

It is known that swarms of earthquakes generally follow a volcanic activity,* especially in the Pelée-type volcano.

Showa-Shinzan born in the eastern foot of Volcano Usu in the south-western part of Hokkaido during 1943-1945, is a remarkable example in the world of this type of activity (Minakami 1950, Minakami 1951). This activity lasted for twenty three months beginning at an earthquake of December 28, 1943 and ending at the formation of a lava dome in the end of October, 1945. As in the usual Pelée-type volcanoes (LACRoIX 1904), swarms of earthquakes occurred in this period of volcanic activity.

The author found out that those earthquakes were clearly recorded on the seismographs in the stations of Muroran $(\triangle=25 \mathrm{~km})$, Mori $(\triangle=54 \mathrm{~km})$, Sapporo $(\triangle=69 \mathrm{~km})$, Asahikawa $(\triangle=155 \mathrm{~km})$, Urakawa $(\triangle=163 \mathrm{~km})$ and even of Tomisaki $(\triangle=852 \mathrm{~km})$. The author would like to get some clues to mechanism of the formation of a new lava dome through the investigation of the seismograms recorded at the surrounding stations.

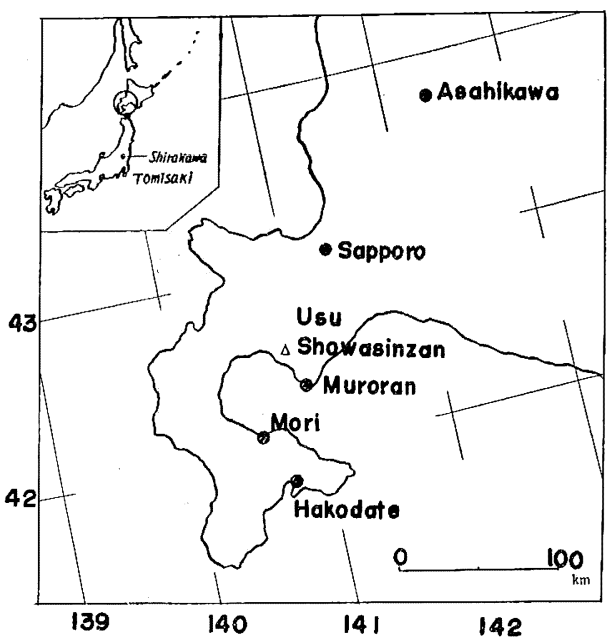

Fig. 1. Volcano Usu and adjacent weather station (Muroran, Sapporo, Mori, Hakodate and Asahikawa).
Showa-Shinzan is situated 2.5 kilometers east of Volcano Usu which is located in the south-western part of Hokkaido. During 1943-1945, a part of Fukaba Village covering 300 acres of farmland upheaved by the volcanic activity forming a roof mountain, then a fresh lava dome (or spine) grew up in the central part and finally a new mountain of $406.9 \mathrm{~m}$ a.s.1. (September 1945, surveyed by the Geographical Survey Institute) appeared at the end of the activity (Minakam 1951).

Volcano Usu is situated to the south of Lake Toya as shown in Fig. 2 and includes O-usu of Belonite (725 $\mathrm{m}$ a.s.l.), Ko-usu (611 m a.s. 1.), Meiji Shinzan, which was formed in 1910 (OMORI 1911), and other parasite volcanoes.

\footnotetext{
* Omori 1911, Omori 1916, Minakami 1950, 1951, Kizawa 1951a, 1951b and Lacroix 1904.
} 
Since Hokkaido had been undeveloped and scarcely populated before the 19th century, no record of eruption prior to 1663 has been found in chronicles, and studies on volcanic activities thereafter are small in number up to 1853 . According to the studies by T. Kato, F. OMORI and others, the remarkable eruptions since 1663 are recorded as follows (Minakami and Ishikawa 1951, Omori 1911):

(1) August 16, 1663

(2) January 23, 1768

(3) March 9 July, 1822

(4) April 13 May, 1855

(5) July 19 October, 1910

T. IsHIKAwA and others reported the formation process of Volcano Usu and the silica content of volcanic rocks as follows (Ishikawa 1947, Minakami 1951, IshiKawa 1953, IsHIKawa 1955, IsHiKawa 1956):

1) Formation of the somma: The somma is composed of lava flows and fragmented ejecta. The silica content of the rock is normally from 51.34 to 52.4 per cent.

2) Formation of the central cone: There are two domes, the O-usu and the Ko-usu, in the central crater on the top of the somma, and they have silica contents of 68.3 and 71.3 percent respectively.

3) Explosion at the foot of the O-usu dome: Although the period of activity

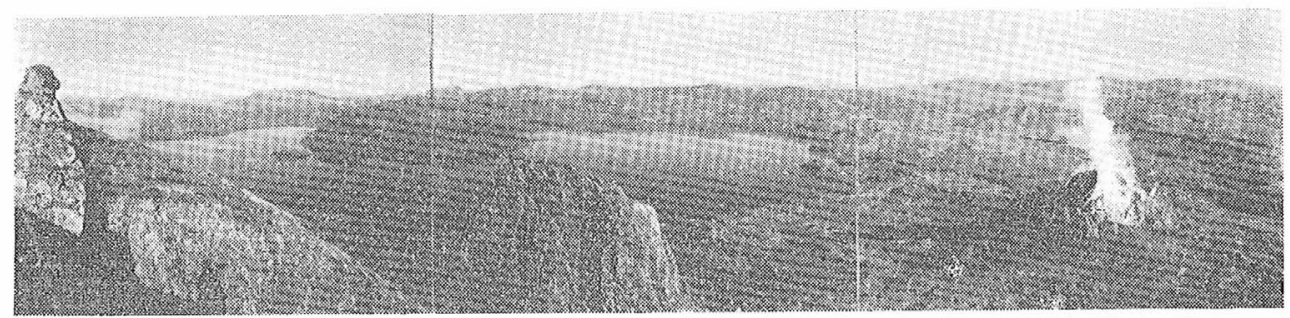

Fig. 2.(a) Showa-Shinzan and Toya Lake viewed from O-usu (After T. KокшвU).

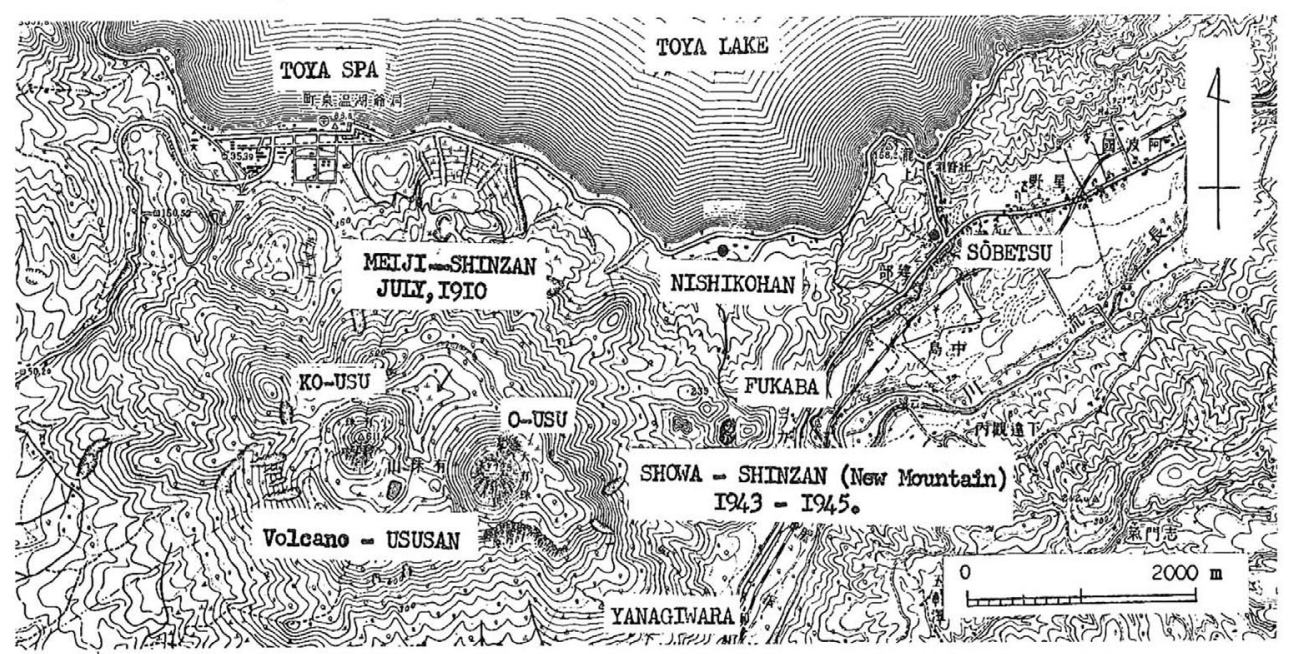

Fig. 2.(b) Topographical map of Volcano Usu, Showa-Shinzan and Meiji-Shinzan. 
is not made clear, the Minami-Byôbu-Yama mud stream which spread over the southern part of the mountain was started by this eruption.

4) Explosion at the foot of the Ko-usu dome in 1822: By this eruption two craters were newly formed near the Ko-usu dome, and the Bunsei mud stream issued spreading over the south-western part of this crater.

5) Explosion at the eastern base of the O-usu dome in 1853: A part of the formation of the O-usu dome was blasted away by the explosion and the Tateiwa mud flow went down toward the eastern foot.

6) Remarkable eruption at the northern foot of the volcano in 1910: As the results of this eruption, forty five craterlets were newly opened and a mountain was newly formed by the upheaved ground.

7) Recent eruption during 1943-1945: Many remarkable swarms of earthquakes, sudden eruptions, and a development of a lava dome on the newly formed mountain are the chief events of the eruption (Showa-Shinzan).

In the above processes of the volcanic activity, it would be a distinguished feature that the lava did not flow out of the crater due to its high viscosity [analysts: Y. Kitano and A. TAnaKa (1951) $69.96 \%$ of $\mathrm{SiO}_{2}$ content], [(a) 69.74-(b) $68.26 \%$ by K. YAGI (1951.) ], and that fresh lava of high temperature rose up as a red heat iron column, being coated with tuff or clay material, sometimes laying pebbles of surface layer on its top (OMORI 1916, Omori 1918, Minakami and others 1951).

Another remarkable feature in this volcanic activity is the fact that distinct earthquake swarms preceded the eruption for a period ranging from a few days to a few months.

\section{The earthquake swarms that occurred during the volcanic activity of Usu and the formation of Showa-Shinzan}

\section{(i) Seismometric Observations}

The volcanic activity related with the formation of Showa-Shinzan began with many remarkable earthquakes around Volcano Usu from December 28, 1943. The hypocenter slowly travelled eastwards, then northwards in April 1944, and upheaved a part of Fukaba village by about fifty meters until June 23, and on that day the eruption occurred and lasted to October in this year. Shortly after the eruption, a lava dome appeared from the crater at the rising area, which grew and developed more and more until October 1945, accompanied with numerous earthquakes. About October 1945, the lava dome being completely formed, the recent remarkable activity came to an end. These series of remarkable earthquakes started to be recorded on the seismographs at Muroran and Mori Weather Stations on December 28, 1943. On the following day the seismograph in Sapporo District Meteorological Observatory (DMO) also recorded a similar earthquake swarm. Thus numerous series of earthquakes increased in frequency and in intensity up to December 30. On this day the seismograph in Muroran recorded fifty one earthquakes, which proved to be the largest frequency during the whole period. Then the frequency decreased exponentially coming to an end on January 27, 1944. This frequency curve was similar to the aftershock decay of a general tectonic earthquake. INoUYE (1948) issued an interesting result comparing this change with the frequency curve of felt earthquakes observed at Toya Hot Springs. Minakamr (1951) discussed the relation between the development of earthquakes and volcanic activities 
based on the number of felt earthquakes observed at Sobetsu Village and others. IsHIKAWA (1951) prepared a graph of intensity distribution of the strong earthquake of January 5 and described its relationship with the deformation around Volcano Usu in detail.

The author prepared frequency charts of one day, ten days and one month after close investigation of seismograms of Muroran, Mori and Sapporo. Fig. 3 shows these daily frequencies in Muroran. Since they are the unique instrumental data during the whole period of volcanic activity and indications of earthquake swarms development for these different stations, greatest attention is given to the preparation of these charts. Since Showa-Shinzan's active period lasted twenty three months, the author of the present paper is afraid that the above mentioned seismograms might include tectonic earthquakes or volcanic earthquakes of other sources (for instance, Komagatake or Tarumae) and microseisms. Therefore, every effort was made to exclude the extraneous traces from these seismograms, by comparing seismogram patterns or other features, and referring to the Geophysical Review and Japan Seismological Bulletin and the author has defined the earthquakes caused by the formation of Showa-Shinzan.

The seismograph in Muroran Weather Station is an old Omori's portable seismograph with a recorder of two horizontal components, magnification of 50 and period of 2 seconds. It is regrettable that it has no damper, but it has worked with a constant accuracy during the whole period as described below. It served in the comparison of earthquake swarms and volcanic activity. The seismograph of the Sapporo DMO are of Wiechert-type, with recorders of horizontal and vertical components, its magnification being 110-107 and the period 5-4 seconds. The Wiechert-type seismograph of the Mori Weather Station has a magnification of 76-71 and a period of about 4 seconds. These constants are listed at the end of this paper.

In Fig. 4 we can recognize that the earthquake frequencies in Muroran, Mori and Sapporo decrease with the increase of epicentral distance, and the patterns are similar to each other, representing earthquake-swarms originated from the same volcano, and that the frequency curve shows two clear maxima. The former corresponds to the initial stage* of December 1943, while the latter corresponds to March, 1945. In the former the frequency jumps to the first maximum and decreases exponentially forming an actue protrusion. In the latter the curves on both sides of the maximum form gentle slopes representing a clear contrast to the former. We shall designate here the former, lasting for about four months, as "Group A", and the latter, for about one year from October 1944 to October 1945, as "Group B".

Therefore, it is noteworthy that there is no record of earthquakes during the period from April to October, 1944. During the most part of this period (June 23-October 31, 1944), the successive violent and moderate eruptions occurred at the newly formed crater of Showa-Shinzan, and many earthquakes that occur immediately below the rising area, have been observed every day at the neighbourhood of the crater.** It is to be noted that, the earthquake swarms occurring in

* Fukutomi, Ishikawa and Minakami (1951) prepared the frequency diagram of perceptible Earthquakes at Toya Hot-springs and Osaru Village during the Pre-volcanic Stage (December 28-January 12).

** Minakami, Ishikawa and Yagi (1951). 

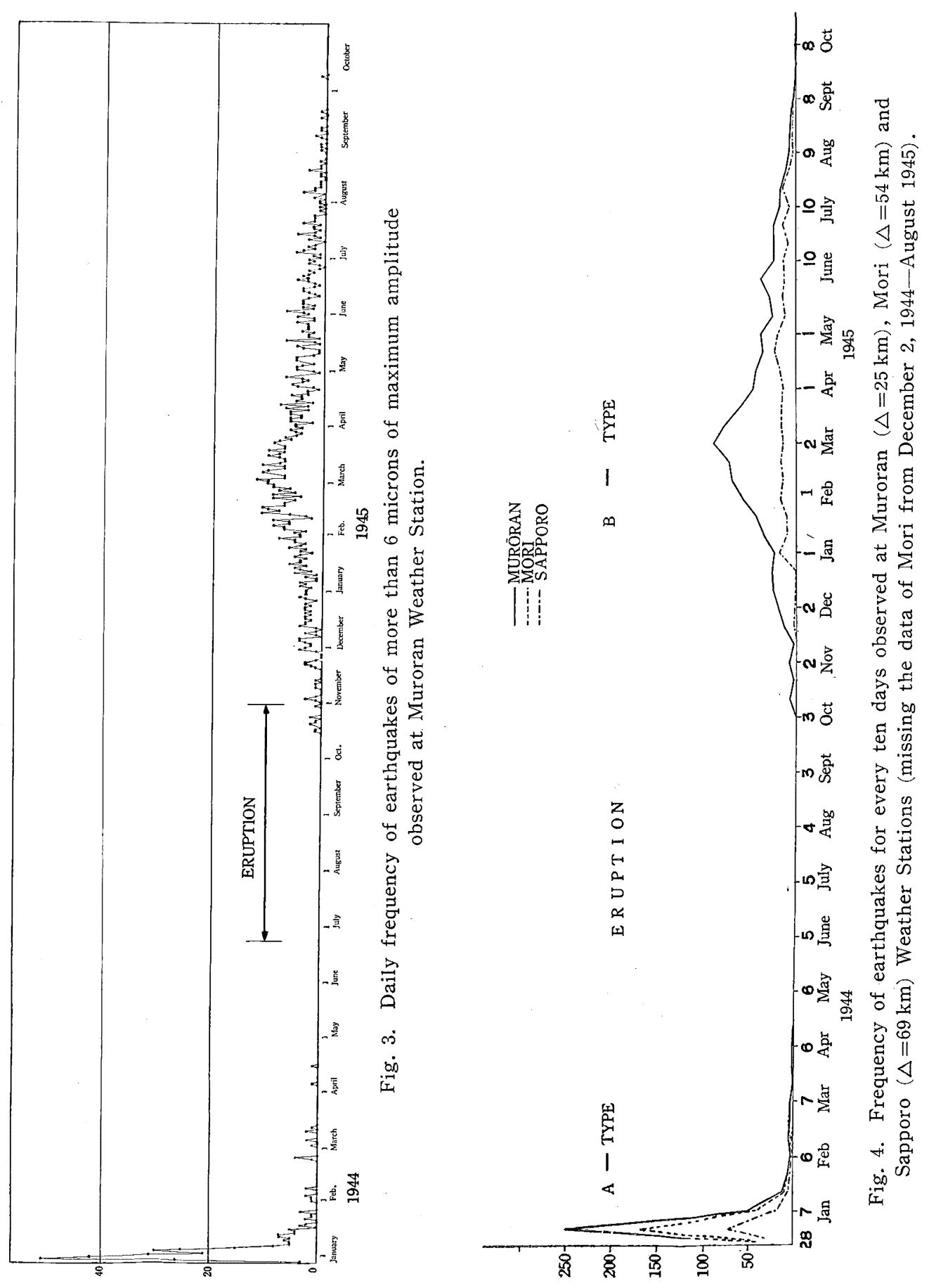
the period of open crater during eruption differ very much in character from those of the A- and B-group earthquakes which occur in the period of closed crater, and have not been observed at any station farther than Muroran.

This earthquake swarms occurring between the A-and B-group, as can be seen in Figs. 3 and 4, will be designated as E-group and should be discriminated from the former two groups.

(ii) Relation between the volcanic activities of the recent eruption of Usu and the earthquake swarms that occurred during the whole period of these volcanic activity.

On the basis of the investigations made chiefly by Fukutomi (1945), Ishikawa (1951), Minakami (1951) and Mimatsu (1951), the development of the recent eruption through the whole period is divided into the following three stages of volcanic activity, which are considered by the present author to correspond well to the earthquake activity mentioned previously.

1) Pre-volcanic stage, December 28, 1943-June 22, 1944 : Corresponding to A-group earthquakes, almost all of them being. A-type earthquakes.

2) Paroxysmal eruption, June 23, 1944-October 31, 1944: Corresponding to Eruption earthquakes.

3) Birth and development of lava dome, October, 1944*-October, 1945 : Corresponding to B-group earthquakes, almost all of them being B-type earthquakes.

Every ten-day frequency curves are shown in Fig. 4, which represent the observations at Muroran, Mori and Sapporo. These frequencies decrease with distance and their patterns are similar to each other, and show remarkable difference in characteristics from those three groups of earthquakes, or A-group, Eruption and B-group (c.f. Figs. 8, 9 and 10) which coincide with the above-mentioned three stages of volcanic activities.

\section{1) Pre-Volcanic Stage}

The recent catastrophic eruption started with the first attack of the perceptible earthquake on December 28, 1943. In this stage, A-group earthquakes, occurred in an underground area below the north-west foot, as already mentioned, and just beneath the Volcano Usu, but since the active center could not break through the lava dome of Ko-usu and O-usu, it travelled gradually eastwards along the Ko-usuO-usu tectonic line (c.f. Fig. 2) from the beginning of January and further to Yanagiwara Village (Ishikawa 1951, 1955, Minakami 1951). Afterwards, the center of the rising area moved northwards along the weak line encircling the crater and caused upheavals and cracks in the ground in Fukaba Village by the beginning of April. Showa-Shinzan was formed by the activities in the following 18 months.

It would be one of the noteworthy phenomena that the adjacent ground has risen rapidly immediately after the most part of the earthquakes around Volcano Usu, as can be seen in Figs. 3 and 4 , had occurred during the first decade of January.

* MrNaKAmi (1951); referred to this type of earthquakes as C-type earthquakes. 
IsHIKAWA (1947, 1953) and others explained this movement of the hypocenter as an intruding and extruding of magma.

With the appearance of A-type earthquakes magma finds its passage, and rather fluidal magma moved from the north-western foot of Usu to Yanagiwara Village generating earthquakes and fissures. Magma moved along the fissure previously formed to Fukaba Village during April to June 22. Accordingly, there was no cause of a strong earthquake.

InOUYE (1948) gave an interest. ing explanation of the relation between the direction of fissure and the initial movements of the earthquake.

Minakami (1951) investigated these earthquakes and found that their hypocenters of the earthquakes that occurred during July 1944, lay between $1.5 \mathrm{~km}$ and $5.0 \mathrm{~km}$ below the southern side of the volcano.

\section{A-type earthquakes (December 1943} -April 1944) and B-type earthquakes (October 1944-October 1945)

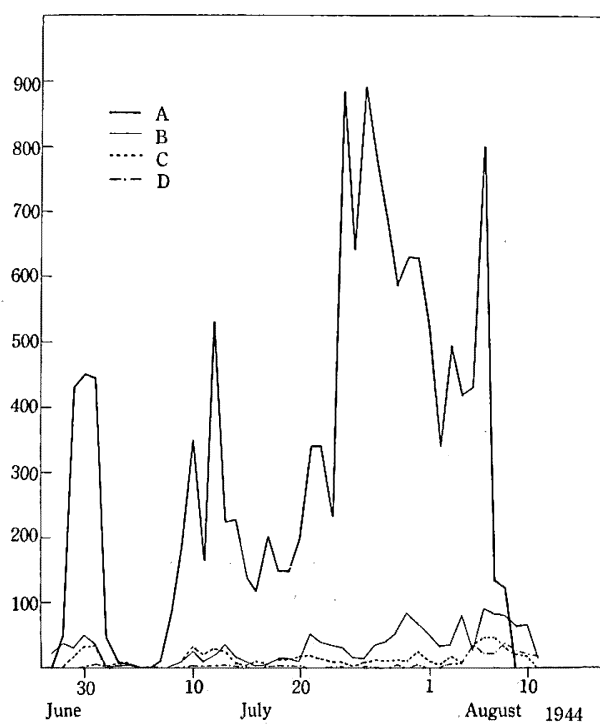

Fig. 5. Frequency of earthquakes for every day observed at the five stations in the paroxysmal eruption. (after T. MiNAKam's observation). (A) Hukaba (Fukaba), (B) Sobetsu, (C) Kami-Osaru, (D) Toya Spa (c.f. Fig. 2).

There is a clear discrimination between A and B-type earthquakes. The Atype earthquake is similar to an ordinary tectonic earthquake, and it is a noteworthy phenomenon that the pattern of wave form in the A-type always includes short-period ripples before or after S-phase appearance without exception, as can be seen in Figs. $8 \sim 10$, while the B-type includes no ripples.

It is difficult to discriminate $\mathrm{P}$ - and S-phases in the B-type, its pattern being of spindle-form (Fig. 10). Each of the earthquakes of this type has almost the same period and their are similar to each other. The problem of amplitude and period will be discussed in my following report. The patterns of types $\mathrm{A}$ and $\mathrm{B}$ are shown in Figs. 8, 9 and 10. However, S-phase appeares sharply in the Atype, and not so apparently in the B-type.

The relation between the maximum amplitude of the A-type earthquake and frequency is represented by

$$
N A^{m}=\text { const.* }
$$

where $A$ is the maximum amplitude and $N$ the occurrence frequency.

As a result of calculation,

$$
m=1.8 \quad \text { (mean value) (c.f. Fig. 6) }
$$

\footnotetext{
* Ishimoto, M. and K. IIDA, 1939.
} 


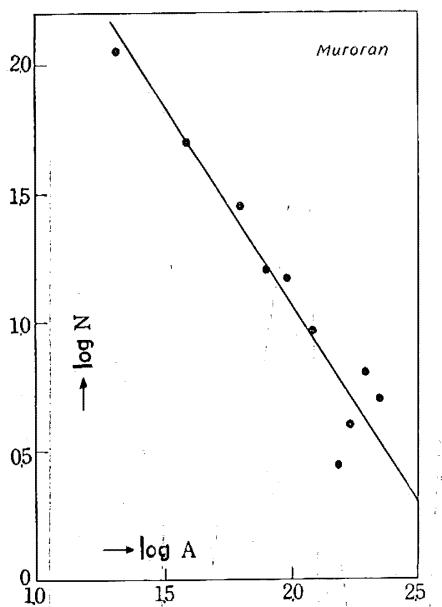

(a)

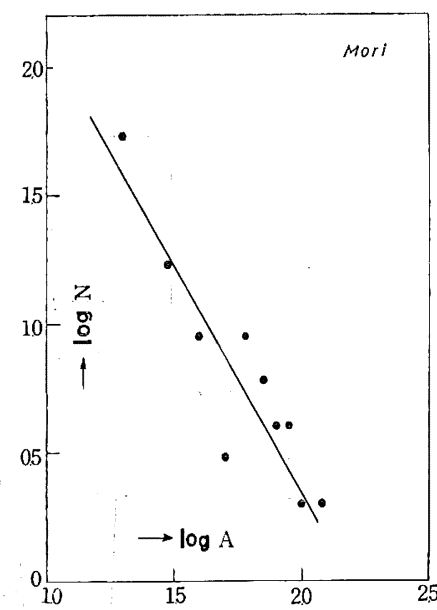

(b)

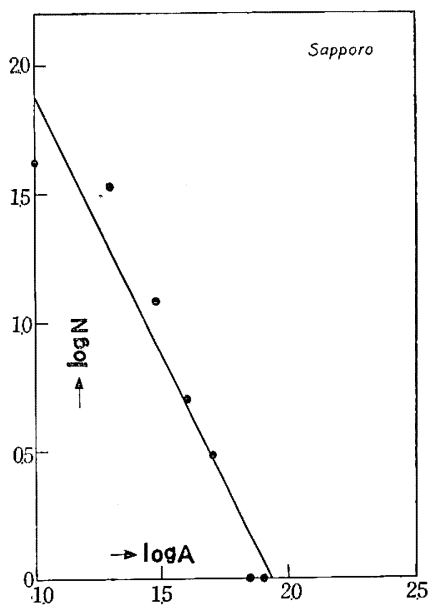

(c)

Fig. 6. Relation between frequency of A-type earthquakes $(N)$ and maximum amplitude (A), December 28, 1943-April 1944. (a) Muroran, (b) Mori, (c) Sapporo

This is substantially the same as the value calculated from the observational data up to now for many tectonic earthquakes (IsHimoto and IIDA, 1939).

The relation between the maximum amplitude of the group B earthquake and frequency is represented similarly by the following formula;

$$
N A^{m}=\text { const., }
$$

as shown in Fig. 7. However, in this case the value of $m$ differs from the former and is obtained by the method of least squares, as

$$
m=3.5 \quad \text { (Sapporo), }
$$

which is close to the value (Minakami 1956 and NAKAmura 1957) obtained from observations of the earthquakes that occurred during the volcanic activities of Volcano Asama, Sakurajima and others.

An earthquake of the A-type of $22 \mathrm{~h} 55 \mathrm{~m}$ on January 5, 1944, and that of $09 \mathrm{~h} 48 \mathrm{~m}$ on January 9, 1944.

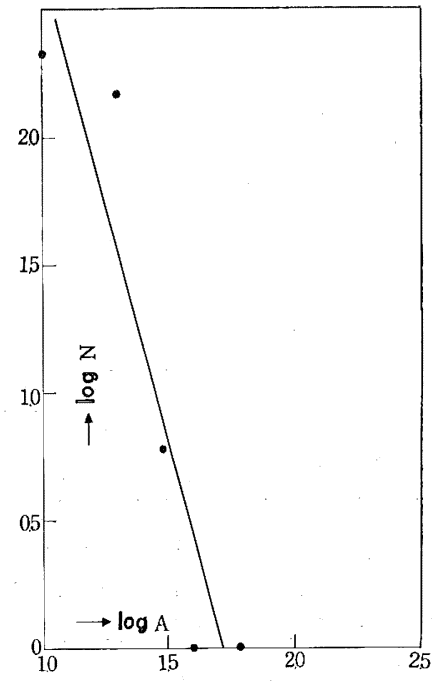

Fig. 7. Relation between frequency of B-type Earthquakes $(N)$ and maximum amplitude (A), October 1944-October 1945, Sapporo.

As stated above, an earthquake of the A-type shows a similar character to general earthquakes and rather strong earthquakes occurred in the initial stage of the pre-volcanic activity. The number of these earthquakes is thirteen during December 1943 and January 1944, of which the earthquakes on January 5 and 9 
are the most remarkable. Ishikawa (1947) and Minakami (1951) mapped the intensity distribution of the former, the hypocentre of which is considered to lie in the north-western foot of Volcano Usu.

These two earthquakes were recorded also on the seismographs of other weather stations. For example, the former was recorded on the seismographs (magnification 50) of Shirakawa Weather Station of $605 \mathrm{~km}$ epicentral distance, and the latter on the Wiechert's seismograph of Tomisaki Weather Station of $852 \mathrm{~km}$ epicentral distance.

The magnitudes $(M)$ of these earthquakes are obtained as follows (Tsubor, Ch., 1954):

$M=1.73 \log \triangle+\log A-0.83$, where

$\triangle:$ Epicentral distance in $\mathrm{km}$

$A$ : Maximum amplitude in micron.

In the former

$$
\begin{aligned}
& M=4.7 \text { (Mori), } \\
& M=4.6 \text { (Sapporo), }
\end{aligned}
$$

are obtained using the records of Mori $(\triangle=54 \mathrm{~km})$ and Sapporo

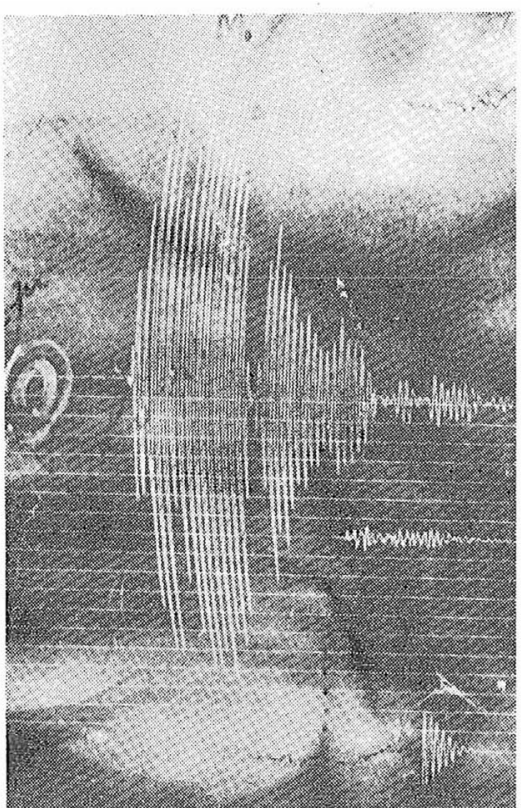

a) Recorded at Muroran $(\triangle=25 \mathrm{~km})$, Seismograph Magn. $\times 50$ (E-W comp.) Fig. 8, Seismograms of the A-type earthquake on January 5, 1944.

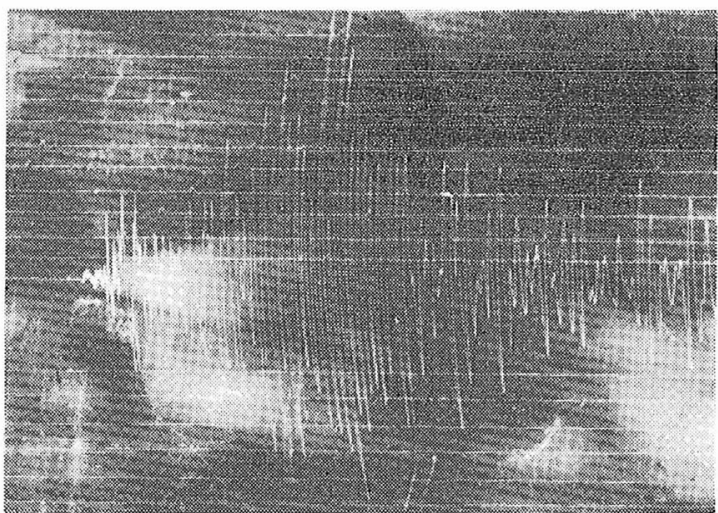

b) Recorded at Mori $(\triangle=54 \mathrm{~km})$, Seismograph Magn. $\times 85$ (E-W comp.).

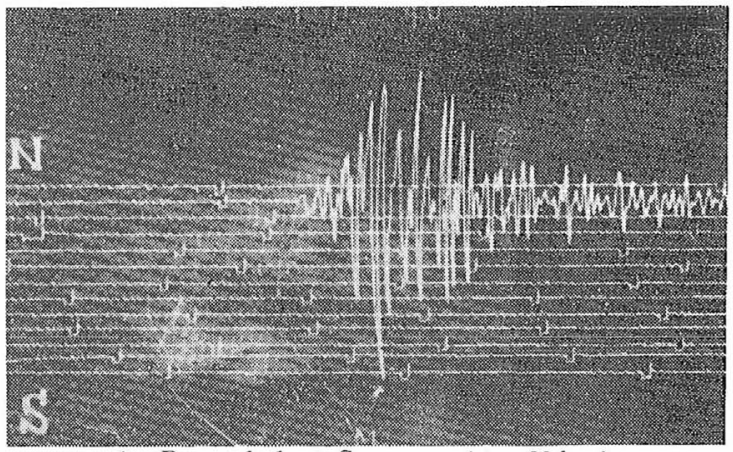

c) Recorded at Sapporo $(\Delta=69 \mathrm{~km})$, Seismograph Magn. $\times 110$ (N-S comp.)

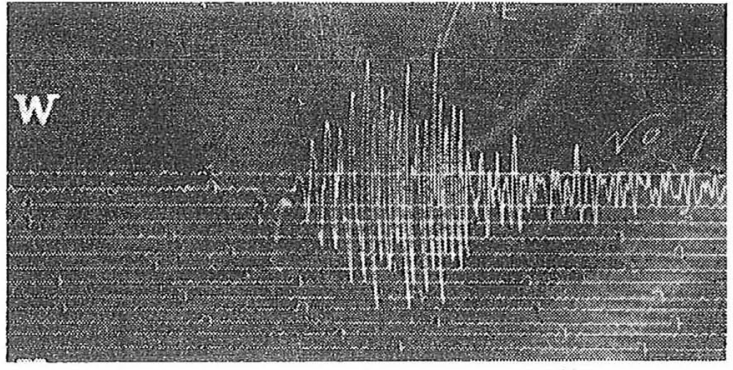

d) do. Seismograph Magn. $\times 108$ (E-W comp.) 


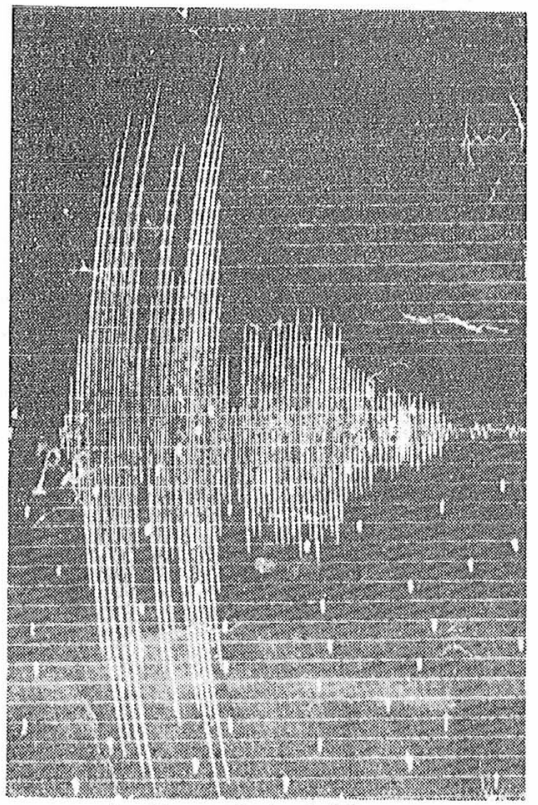

a) Recorded at Muroran $(\triangle=25 \mathrm{~km})$, Seismograph Magn. $\times 50$ (N-S comp.)

Fig. 9. Seismograms of the A-type earthquake, on January 9, 1944.

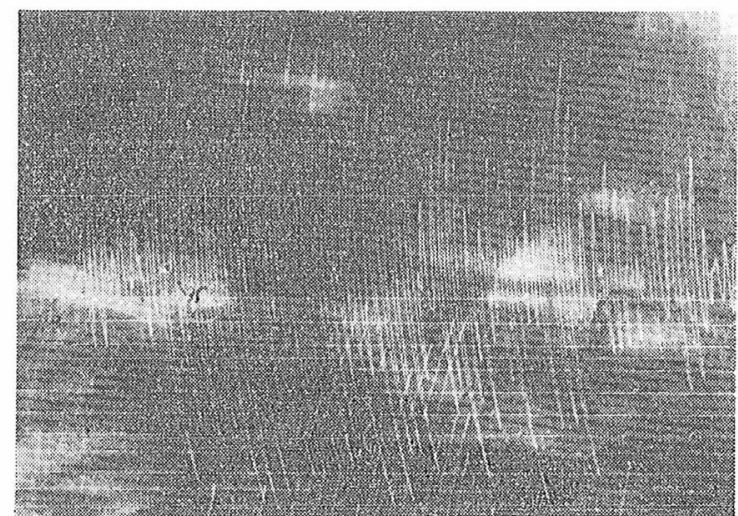

b) Recorded at Mori $(\triangle=54 \mathrm{~km})$, Seismograph Magn. ×85 (E-W comp.)

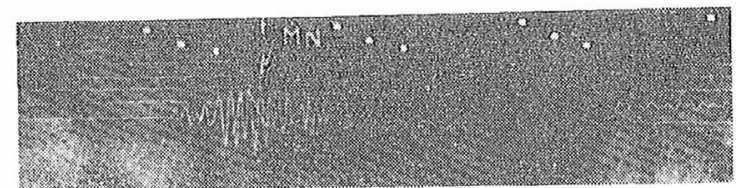

c) Recorded at Sapporo $(\triangle=69 \mathrm{~km})$, Seismograph Magn. ×15 (N-S comp.)

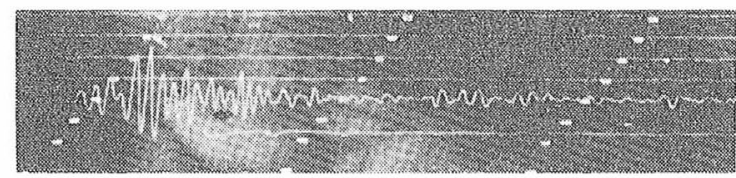

d)

do.

Seismograph Magn. ×15 (E-W comp.)

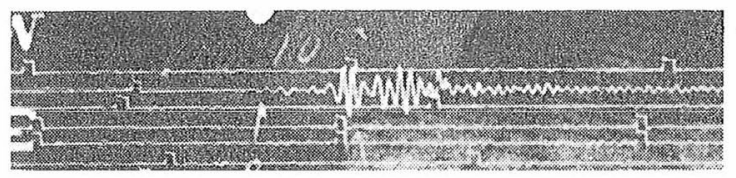

$\leftarrow$ Fig. 10. Seismograms of the B-type earthquakes.

a) May 3, 1945, Recorded at Sapporo $(\triangle=69 \mathrm{~km})$, Seismograph Magn. $\times 104$ (W-E comp.)

b) May 29, 1945, Recorded at $\rightarrow$ Muroran $(\triangle=25 \mathrm{~km})$, Seismograph Magn. $\times 50$ (E-W comp.)

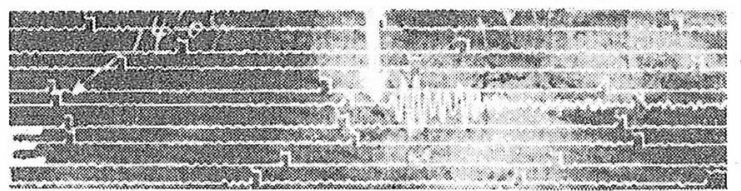

d) June 18, 1945, do.

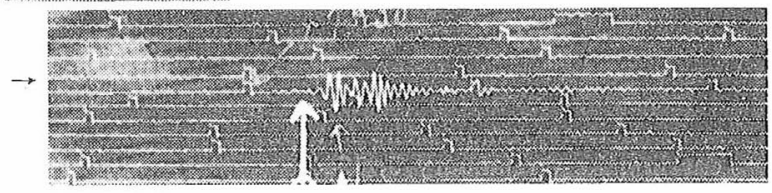

c) May 29, 1945, Recorded at Sapporo, Seismograph Magn. $\times 104$ (W-E comp.) 
$(\triangle=69 \mathrm{~km})$ with the ground coefficient for maximum amplitude (Sapporo 1.1; Mori 0.7) obtained by Katsumata (1955) (These travel-time curves, since the epicenter is the same, will be discussed in the following paper together with the analysis of seismic waves referring to the other travel-time curves of ShowaShinzan).

In the latter, the observations at Mori, Sapporo and Hachinohe $(\triangle=228 \mathrm{~km})$ were used, and

$$
\begin{array}{ll}
M=4.8 & \text { (Mori), } \\
M=4.9 & \text { (Sapporo), } \\
M=4.7 & \text { (Hachinohe), }
\end{array}
$$

were obtained. Then the energy $(E)$ is calculated with the average value, and $10^{18.8} \mathrm{erg}$ and $10^{19 \cdot 0} \mathrm{erg}$ were obtained respectively. This calculation was made by the following formula :

$$
\log E=11.8+1.5 \mathrm{M}
$$

obtained recently by B. Gutenberg and C. F. Richter (1956), where $M$ denotes magnitude.

\section{2) Paroxysmal Eruption}

The rising area reached $50 \mathrm{~m}$ in height at Fukaba village and the first explosion took place at $8 \mathrm{~h} 30 \mathrm{~m}$ on June 23, 1944, in the central part. Rising of vapor and of mud and eruption of ashes followed in turn. IsHIKAwA described that the mud ascension was just like a fountain. LACROIX (1904) previously reported that mud eruption occurred at the summit prior to generation of nuée ardente* in Mt. Pelée eruption, and we found the same took place. After IsHikawa the initial mud eruption was not caused directly by the gaseous pressure produced by fresh lava, but by steam-pressure of underground water produced by the heat of fresh magma.

A terrible explosion, which originated from the intruding fresh magma, took place on July 2, and another followed on July 3, discharging a vast amount of ash of $2 \times 10^{6}$ metric tons and $10^{5}$ metric tons** respectively. Since the first outburst on 23 June, violent and moderate explosions occurred successively until October 31, though the characters of paroxysmal eruptions varied gradually. During the mud eruption two craters were made, and seven in total were made by the end of October of this year.

These craters were aligned on a semi-circle and the lava dome appeared in the central part of the circle.

\section{Eruption Earthquakes}

In Fukaba village, more than one hundred earthquakes were counted daily since the middle of June, though all of them, as stated before, expressed the feature of an earthquake*** occurring in the period of open crater in eruption, i.e. that the hypocenter lies in the extremely shallow layer near the rising crater and its seismic waves are damped rapidly near the epicentral area.

* Lacriox, 1904 ; Perret, 1937 : Anderson and Fiett, 1903.

** Minakami, Ishikawa and Yagi, 1951.

*** Sassa, K., 1935, made seismological investigations around Volcano Aso. 
Minakami (1951) selected five points around the crater, or Sobetsu, Fukaba, Yanagiwara, Kamiosaru and Usu and observed the volcanic earthquakes with high sensitive seismograph (magnification about 200 350) for the period from June through August, 1944. The resulting daily frequency remarkably decreased in a short distance. For instance, Fukaba recorded 445 earthquakes on July 1, while Sobetsu $2 \mathrm{~km}$ apart from it recorded 38 and Toya $4.2 \mathrm{~km}$ apart from it recorded only seven earthquakes on the same day (cf. Fig. 5).

\section{3) Birth and Development of Lava Dome}

There was no eruption after November 1, 1944. In the middle decade of November a black block of triangle-form appearing from the crater was seen from the western coast of the lake. This was the solidified magma that protruded from the earth-surface. It developed gradually by the end of October 1945 with-

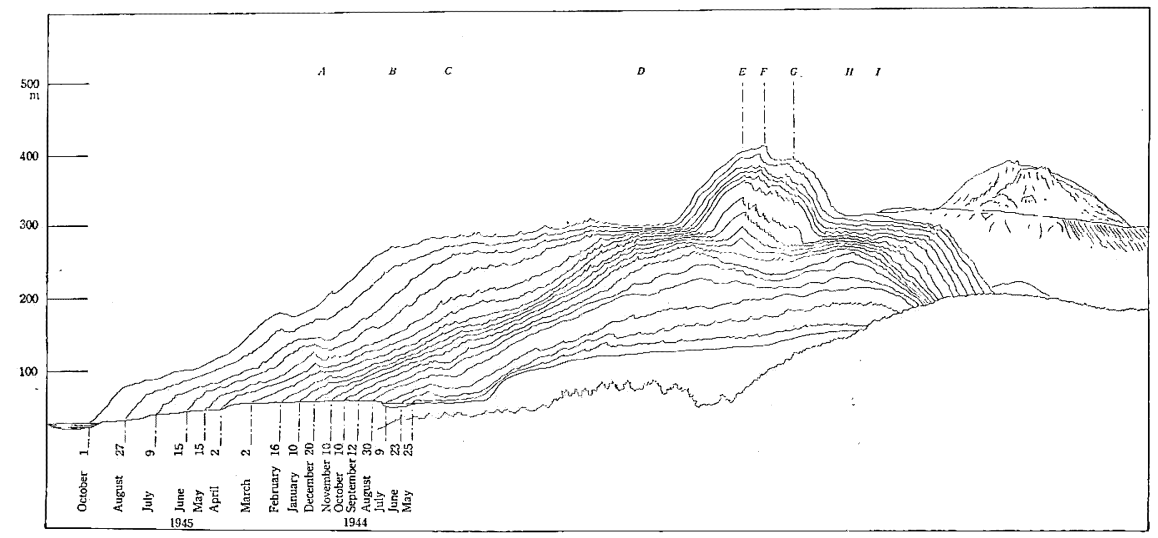

Fig. 11. Developments of the newly formed "Showa-Shinzan" (after M. Mimatsu).

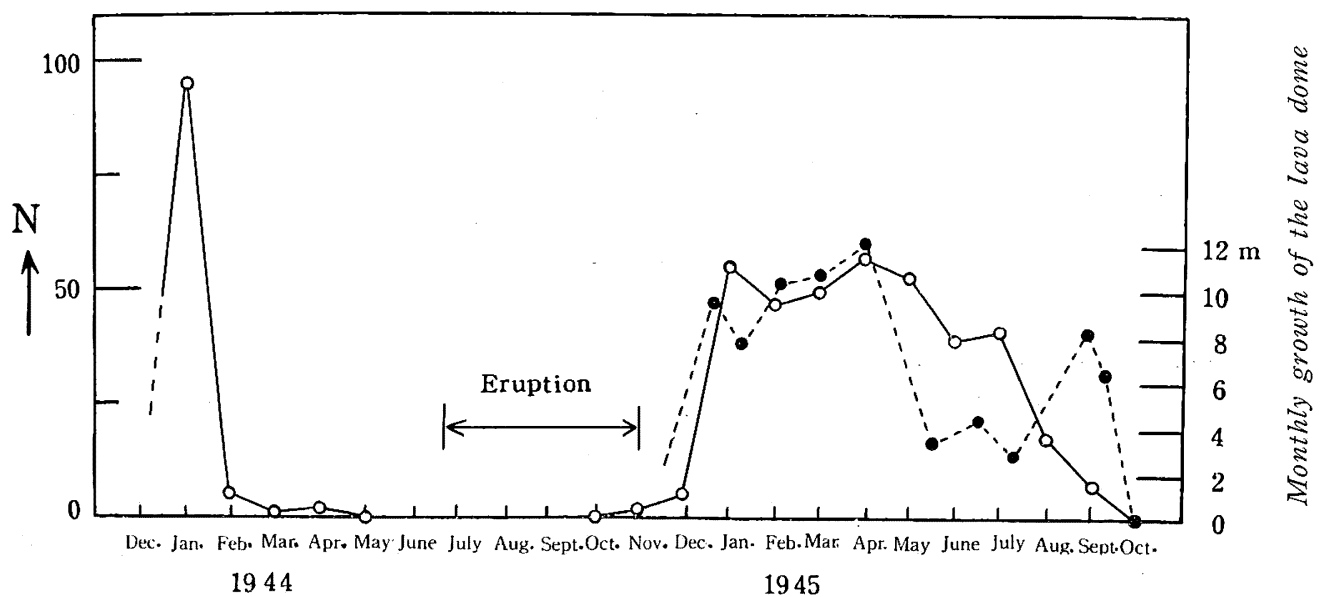

Fig. 12. Relation between the monthly frequency of earthquakes by the observation at Sapporo and the monthly growth of development of the lava dome. (November 1944-October 1945) Solid line: Frequency of earthquakes observed at Sapporo $(\triangle=69 \mathrm{~km})$ Broken line: Monthly growth of development of the lava dome. 

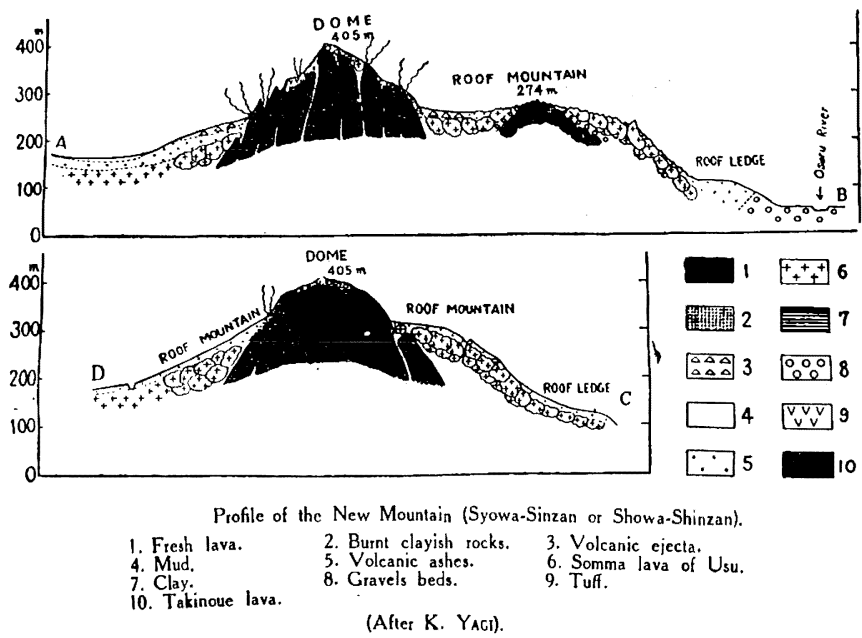

Fig. 13. Profile of the new mountain (Showa-Shinzan).

out eruption. The height measured 406.9 meters a.s.1. being 110 meters higher than the roof mountain, and its diameter was estimated at 300 meters (after Fukutomi 1945 and IshiKawa 1947, 1956).

Fig. 12 including the monthly development of B-type earthquake-swarms clearly indicates a perfect coincidence with the birth and development of the lava dome. When the dome appeared on November 1944 soon after the end of the eruption, the earthquake swarms occurred with increasing frequency and ended with the completion of the dome in October 1945. These earthquake swarms, which are called B-type earthquakes, are widely different from those of the former two types (cf. Figs. 3 and 4). On the other hand, as can be seen in Fig. 11, Mimatsu (1949) recorded the morphological development of the forming Showa-Shinzan in detail throughout the activity. The author calculated the growth on the vertical intersection of the profile through points $A, B, C, D, E, F, G, H$ and I. A comparison of these results with the corresponding monthly frequency of earthquake swarms (Sapporo), as seen in Fig. 12, shows that the growth of E, F and G lines which interesect the lava dome follows well the frequency curve of the B-type earthquakes, and clearly differs from the growth of other lines which interesect the roof mountain. (cf. Figs. 11, 12 and 13)

In other words, this coincidence shows that the frequency of B-type earthquakes has a close relation with the birth and development of the lave dome, which is one of the most remarkable phenomena in the recent activity of Usu.

Thus, the author was led to a deduction that the change of characteristics in the volcanic activities has a close representation of the seismic waves. And it would be an interesting phenomenon that B-type earthquakes, which can be recorded clearly at Sapporo $69 \mathrm{~km}$ apart from the volcano, has a different nature from an E-group earthquake during eruption which is absorbed rapidly.

These problems will be further discussed in my following paper together with seismic wave analysis. 
Now, let us consider the development of an earthquake swarms and the movement of magma during the period.

When the above-mentioned paroxysmal eruption burst out through newly opened fissures or craters on the rising area at Fukaba, the external portion of the intruding magma may be considered to have fallen in temperature and emitted gases, furthermore a considerable amount of volatile matter was discharged and the physical conditions have changed in the magma. On that account, the magma seems to have accelerated its speed of solidification. In order to uplift the viscous magma to and above the earth's furface from its seat through the conduit, a pressure must necessarily have worked inside of the crater.

Consequently, it would be a noteworthy phenomenon that in the course of the stage from about October 1944 to October 1945, the series of B-type earthquakes took place* suddenly.

\section{Remarks on the prediction of volcanic activity}

The prediction of volcanic activity is an important problem from both practical and scientific points of view. In this connection, the author wishes to bring forward some observations about the above-mentioned Volcano Usu of Pelée-type activity.

Prediction of eruption depends upon: (1) Possibility of recognizing the forerunning phenomena, (2) Retardation of eruption to the forerunning. (3) Quantitative relation between the above two phenomena (After Minakami 1956).

As forerunners of volcanic activity we are able to cite volcanic earthquakes, volcanic tremor, tilting of the ground, extension of ground, topographycal deformations, variation of terrestrial magnetism, anomalous change of the earth current, change in the composition of volcanic gas and change of underground temperature, and among them the earthquake due to volcanic activity is considered to be the most reliable for volcanic prediction (Minakami 1950, Minakami 1951, Kizawa 1951 a, Kizawa 1951 b, Kizawa 1952, Omori 1916, YoKoyama 1954), especially of

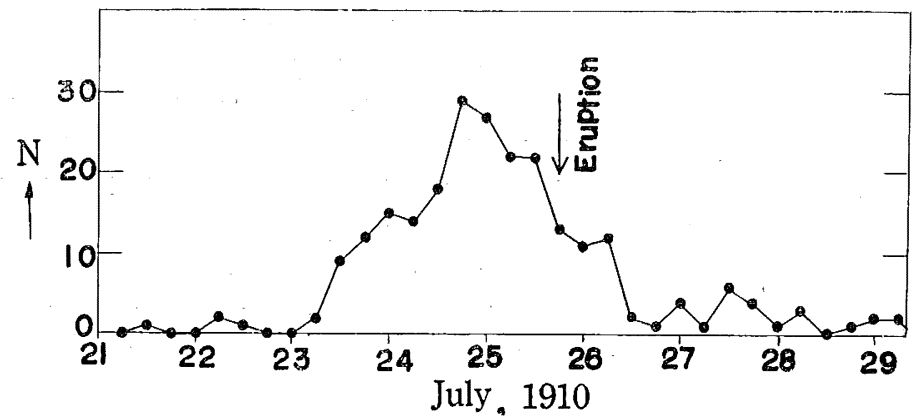

Fig. 14. Frequency of earthquakes observed at Sapporo Weather Station $(\triangle=$ $69 \mathrm{~km}$ ) of July-October 1910. (Volcano Meiji-Shinzan) (after F. Omori)

* There remains an important problem: To what level the magma rose up in the liquid state and when it changed to the solid state? The author considers the change of the seismic wave form would suggest clue to the solution of this problem and is carrying on the investigation. Suggestions on this point will be appreciated. 
Pelée-type. For example, in 1910, during the active period of Meiji-Shinzan earthquake swarms occurred July 21 on the eruption burst on July 25 (Fig. 14). Within a few days prior to the eruption of 1663, 1822 and 1855 remarkable earthquakes were observed. Accordingly, if we can settle the above relations we shall be able to predict an eruption at least a few days or a few months before. In case of the above-mentioned example of Showa-Shinzan. A-type earthquake swarms were clearly observed seven months prior to the eruption (Section 2)

Now, it comes into question, for instance, when A-type earthquakes will change to B-type (cf. Section 2, Figs. 3 and 4). It would be the key to this question to know the change of the earthquake pattern or stage, and the study on this point is still being continued by the author.

The question of prediction further involves geographical conditions. If we are able to watch volcanic activity at a place far from the volcano so that it can be useful for prediction, it will be a great progress. The earthquakes of volcanic activity in 1910 were recorded as can be seen in Fig. 14, on OMORI's seismograph (magnification 15) in Sapporo. In our cases the seismographs in Sapporo, Mori and other towns separated far from the volcano registered similar series of earthquakes clearly (Figs. 3, 4 and Section 2). It would be possible to predict a volcanic activity by means of seismometric observation in a town far from a volcano if we install many seismographs of high sensitivity and analyse the seismic waves recorded on them.

Concluding Remarks_-The A-type earthquake swarms which preceded this catastrophic volcanic eruption changed themselves into the series of E-type and B-type ones in the course of the development of volcanic activity. Furthermore, these A-type and B-type earthquake swarms were recorded clearly on the seismographs even at the Sapporo, Mori and Muroran Weather Stations considerably distant from the volcano. These facts will bring about a remarkable progress to the knowledge on the volcanic earthquake heretofore obtained.

Special attention is paid to the forerunning earthquakes mentioned above, namely the series of A-type earthquakes and to their change into other types, because they give an important clue to the prevention of disasters by eruptions and also throw light on the structure and mechanism of volcanoes and earthquakes.

\section{Summary}

(1) Daily frequency tables of earthquake swarms that occurred during the formation of Showa-Shinzan, one of the Pelée-type volcanoes, i.e. for the period of 23 months, were prepared, making use of the seismograms in Muroran, Mori and Sapporo $(\triangle=25 \mathrm{~km} \sim 69 \mathrm{~km})$.

(2) These frequency curves clearly expressed the three stages 1) prevolcanic, 2) eruptive activity and 3) birth and development of lava dome.

(3) Striking coincidence between the development of earthquakes swarms and three stages of activity is shown and the important relations between them are explained.

(4) The existence of forerunning earthquakes in Pelée-type volcanic activity (as in Volcano Usu) is clearly shown, and possibility of prediction of volcanic activity using seismological observations in a town of considerable distance from the volcano was suggested. 
Table 1. The daily frequency of the earthquakes of more than 6 microns of maximum amplitude observed by seismographs at the Muroran Weather Station $(\triangle=25 \mathrm{~km})$ during December 1943-October 1945.

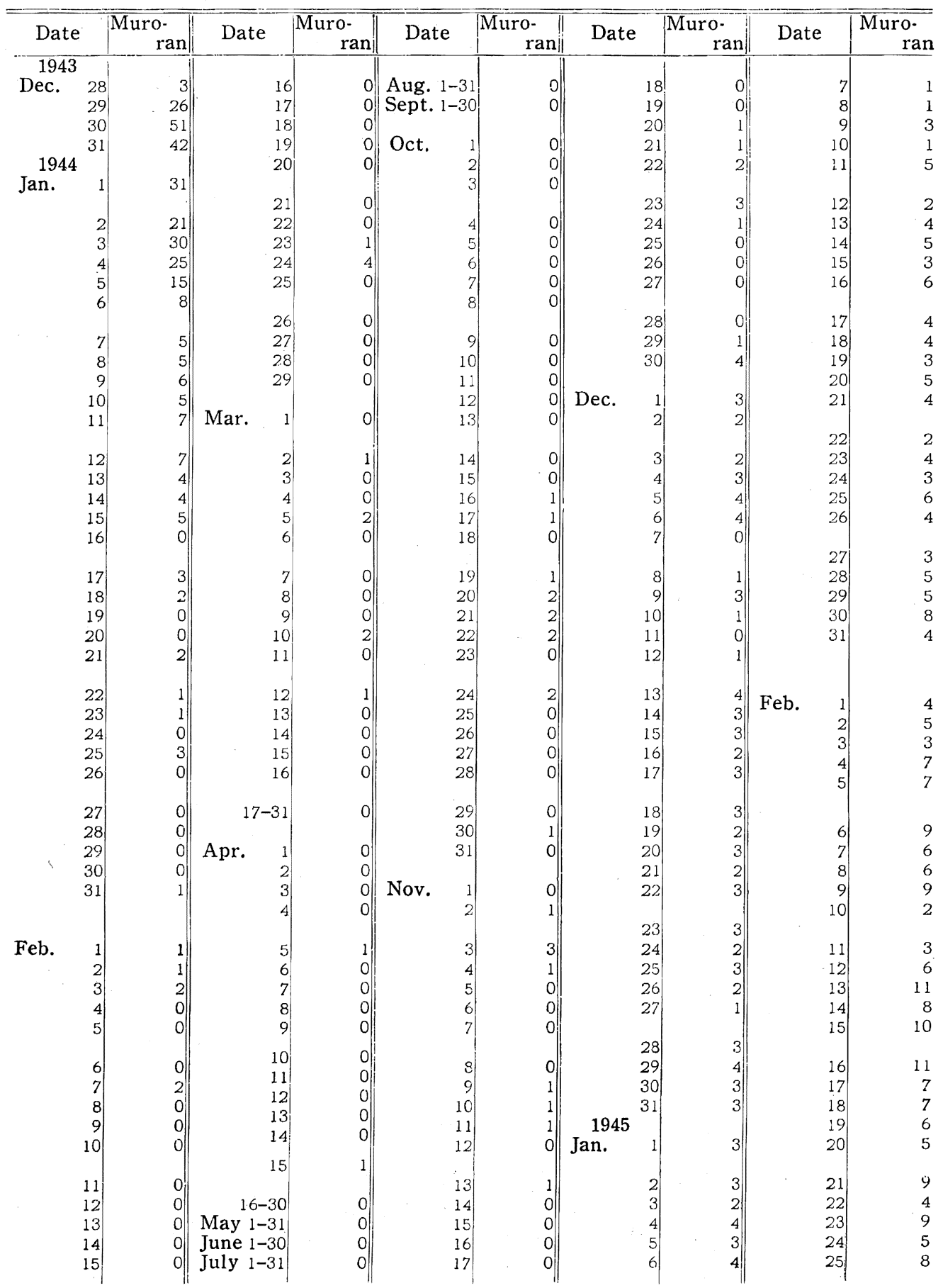




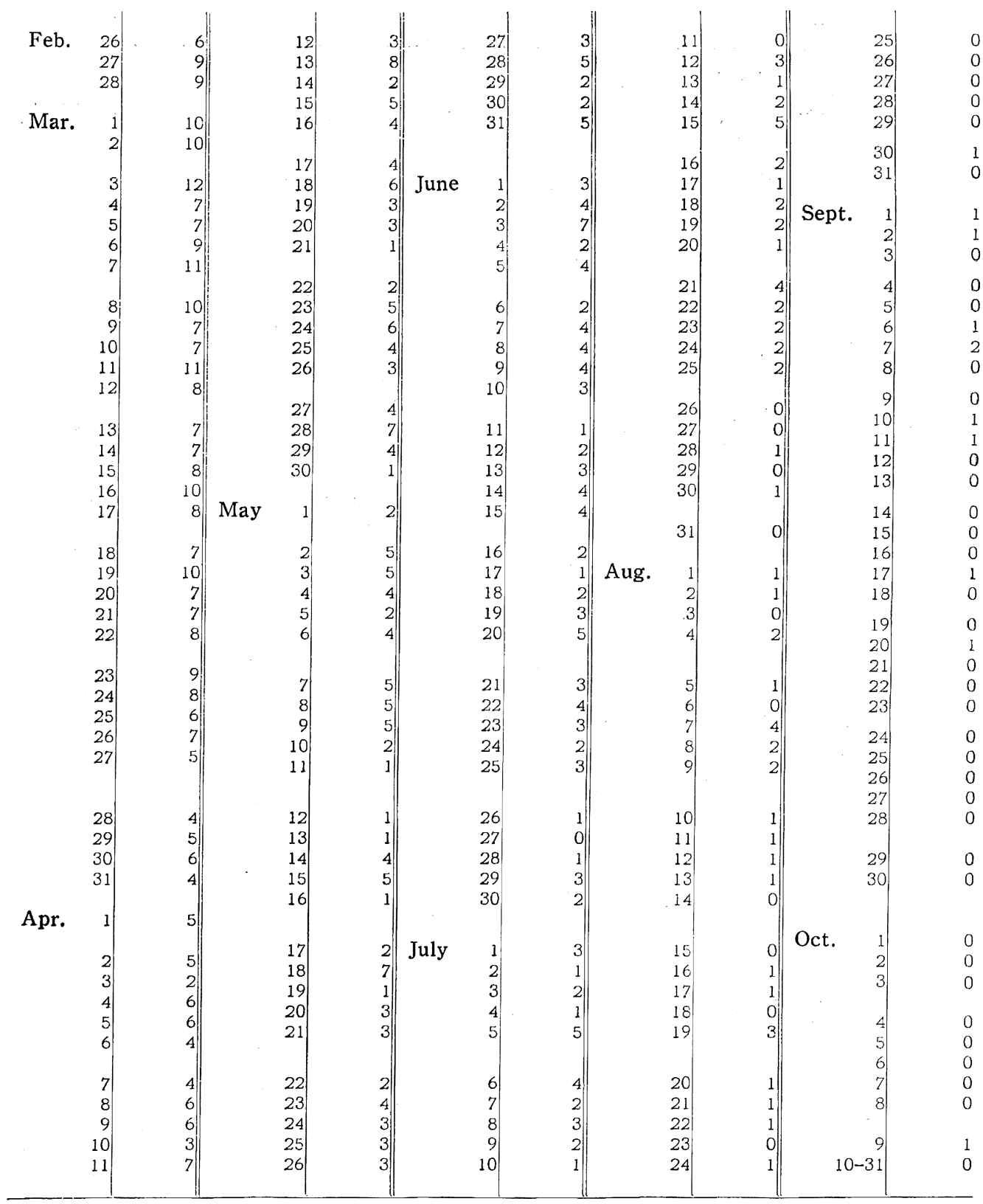

Acknowledgements - In preparing this paper, Prof. T. Ishikawa and Mr. S. Sakuma (Hokkaido Univ.), Prof. H. Honda (Tohoku Univ.), Prof. T. Minakami, Dr. R. Morimoto, Mr. J. Ossaka and Mr. K. Mogi (Tokyo Univ.).

Dr. H. Hatakeyama and Dr. W. Inouye (Meteorological Research Institute) and Dr. T. Hirono, Mr. Y. Shimizu, S. TAKAGI and S. Oor (Japan Meteorological Agency) have kindly discussed the topic with the author and gave him their kind 
encouragement.

Messrs. M. Furuta and E. Minemoto (Seismological Laboratory) assisted in the preparation of this paper.

The directors of Sapporo, Sendai, Muroran and Mori Weather Stations kindly afforded facility to investigate the seismograms.

The author wishes to express his deep gratitude to all of them.

\section{References}

Anderson, T. and J.S. Fuetr, 1903: Report on the eruption of the Sourfriere in St. Vincent, in 1902 and on a visit to Montagne Pelée in Martinique, Part I . Philos. Trans. Roy. Soc. London, A., 200, 353 553.

Foster, H.L. and C. Mason, 1955: 1950 and 1951 eruption of Miharayama, Oshima volcano, Japan, Bull. Geol. Soc. Amer., 66, 731 760.

Fuкuтом, T., 1945: Science (Kagaku), 16, 3 80.

Gutenberk, B. and C.F. Richter, 1956: Progress report, Seis, Laboratory, California Institute of Technology, 1955, Trans. Amer. Geophys. Union, 37, 243 236.

GutenberG, B. and C.F. Richter, 1956: Magnitude and energy of earthquakes, Geofisica, 19, $1 \sim 15$.

Honda, H., 1954: Zishinhado (Wave motion of earthquake), Iwanami-shoten, Tokyo (in Japanese).

Inouxe, W., 1948: On the earthquakes and topographic changes accompanied by the Usu eruption of 1944. Quart. Jour. Seism., 14, 9 24.

Inovye, W. and N. Homma, 1948: On the Usu eruption of 1944. Quart. Jour. Seism., 14, $25 \sim 32$.

Ishikawa, T., 1947: Science and Scientific Educ., 1, No. 1.

Ishikawa, T., 1953: Eruption of Usu volcano, Hokkaido, Japan, 1943 45. Proc. Seventh Paci. Science Congress, Auckland and Christchurch, 2, 368 375.

IsHikawa, T.; 1955: Age of the welded tuffs in northern Japan. Roma, 1955, S.P.A. Tipografica Castaldi, 49, $1 \sim 8$.

Ishikawa, T., 1956: Kita no Kazan, Nire-shobo, Sapporo 6 14.

Isнiмото, M. and K. IrdA, 1939: Observations, sur les Séismes enregistrés par le Microseicmographe Construit dernièrement (1), Bull. Earthq. Res. Inst. 17, 443 478.

Katsumata, M., 1955: Ground Coefficient for Amplitude of Earthquakes, Quart. Jour. Seism. 19, No. $3 \sim 4,77 \sim 80$.

KIzAWA, T., 1951: Volcanic tremor and tilting of ground, Quart. Jour. Seism. 15, 18 34.

KIZAWA, T., 1951a: Geophysical phenomena in relation to volcanic activity (I) (II), Jour. Meteor. Res. 3, 249 260, 277 291.

KizaWA, T., 1951b: Volcanic tremor, Jour. Geography, 60, $28 \sim 31$.

KizaWA, T., 1952: Geophysical phenomena accompanied by volcanic activity, Geophys. Mag., 23, 389 398.

Krakatoa Comm. R.S., 1888: The eruption of krakatoa and subsequent phenomena, London.

Lacroix, A., 1904: La Montagne Pelée et es Eruptions, Paris, Masson et Cie.

Matsuzawa, T., 1933 : Earthquake, Tokyo, Iwanami-shoten.

Mimatso, M., 1949 : Read at E.R.I. (June 1949)

Minakam, T., 1950: On Explosive activities of andesitic volcanoes and their fererunning Phenomena, Bull. Volcanol. 10, 59 87.

Minakam, T., T. IshikaWA, and K. YAGI, 1951: The 1944 eruption of volcanic Usu Hokkaido, Japan, Bull. Volcanol. 11, 45 157 
Minakami, T., 1956: Kagaku-Asahi, (August), 84 89.

NAKAMURA, R., 1957: On the volcanic tremor at Sakurajima, Memoirs of the Fukuoka Met. Observatory, 13, 54 62.

OMORI, F., 1911: The Usu-san eruption and earthquake and elevation phenomena, Bull. Imp. Earthq. Inv. Comm., 5, 1 38.

OмоRт, F., 1916: The Sakurajima eruptions and earthquakes, III, Bull. Imp. Earthq. Inv. Comm., 8, 181 321.

Perret, F.A., 1935: The Eruption of Mt. Pelée 1929 32. Publ. Carneg. Inst., No. 458.

SASSA, K., 1935: Volcanic micro-tremors and eruption-earthquakes, Memoirs of Science, Kyoto Imp. Univ. Vol. 18, 255 293.

Tsuвor, Ch., 1954: Determination of the Gutenberg-Richter's Magnitude of Earthquakes Occuring in and near Japan. Zisin, Ser 2, 7, 185 193. (Journ. Seism. Soci. Japan)

TsuboI, Ch., 1957: Energy accounts of earthquakes in and near Japan. Zisin (Journ. Seismo. Soci. Japan) 9, 229 234.

Yoкоу амA, I., 1954: Geomagnetic studies of volcano Mihara (IV), Bull. Earthq. Res. Inst. $32,17 \sim 33$. 